\title{
Ethnicity and age as factors in sildenafil treatment of erectile dysfunction
}

\author{
Dana A. Ohl ${ }^{1}$ | Vera Stecher ${ }^{2}$ | Li-Jung Tseng ${ }^{2}$
}

${ }^{1}$ Department of Urology, University of Michigan, Ann Arbor, MI, USA

${ }^{2}$ Medical, Pfizer Inc, New York, NY, USA

\section{Correspondence}

Dana A. Ohl, MD, University of Michigan Health System, Ann Arbor, MI, USA.

Email: daohl@med.umich.edu

Funding information

This study was sponsored by Pfizer Inc.

\begin{abstract}
Introduction: Sildenafil has been evaluated in $>16000$ men with erectile dysfunction (ED) in double-blind, placebo-controlled trials.

Aim: To assess efficacy and safety of sildenafil in ED by ethnicity (white, black Asian) and age $(\leq 45,46-60, \geq 61$ years).

Methods: Data were pooled from 38 double-blind, placebo-controlled, flexible-dose trials. Most had starting sildenafil doses of $50 \mathrm{mg}$ once daily, $\sim 1$ hour before sexual activity, with adjustment to 100 or $25 \mathrm{mg}$ as needed.

Main Outcome Measures: Change from baseline in International Index of Erectile Function erectile function (IIEF-EF) domain score assessed with analysis of covariance and a Global Assessment Question (GAQ; "Did the treatment improve your erections?") at endpoint assessed with logistic regression analysis.

Results: 4120 and 3714 men received sildenafil and placebo, respectively 2740 and 2671 White; 407 and 385 Black; 973 and 658 Asian). For sildenafil vs. placebo groups, overall treatment differences for IIEF-EF domain and GAQ were significant for each ethnic and age group $(P<.0001)$; significant treatment-by-ethnicity and treatment-byage interactions were also observed for change in IIEF-EF domain scores $(P<.05)$, with differences significantly greater for White vs. Black $(P<.0001)$, White vs. Asian $(P=.0163)$, and Asian vs. Black $(P=.0036)$ men. A significant treatment-by-ethnicity interaction was observed for GAQ $(P=.0004)$. The OR comparison for GAQ was significantly greater $(P=.0001)$ with sildenafil vs. placebo in White $(O R=11.2)$ or Asian $(\mathrm{OR}=12.4)$ men vs. Black men $(\mathrm{OR}=5.1)$. Adverse-event rates were generally similar, with some age variations.

Conclusions: Sildenafil is effective and well-tolerated regardless of ethnicity or age; however, treatment effects can vary.
\end{abstract}

\section{1 | INTRODUCTION}

Erectile dysfunction (ED), the persistent inability to achieve and/or maintain erections sufficient for satisfactory sexual performance, ${ }^{1}$ is a multifactorial condition that is associated with age, comorbid systemic diseases (eg, cardiovascular disease [CVD], hypertension [HTN], diabetes and depression), certain therapeutic medications (eg, antihypertensives, antidepressants and vasodilators) and various endocrine, neurological and psychological factors. ${ }^{2}$ With the availability in 1998 of sildenafil, the first oral medication for the treatment of ED, the management of ED entered a new era. Sildenafil is an effective and well-tolerated oral agent that is recommended as a first-line therapy for $\mathrm{ED}^{3,4}$ based on data from extensive doubleblind, placebo (PBO)-controlled trials in more than $>16000$ men with ED and nearly 20 years of use in clinical practice. The efficacy and safety data collected during the clinical trials of sildenafil provide a database for investigating factors that may influence and aid in the management of ED in clinical practice. For example, the efficacy and 
safety of sildenafil vs. placebo according to patient age recently were assessed in 11364 men with ED using data from 48 randomised, double-blind, placebo-controlled, flexible-dose sildenafil trials. ${ }^{5}$ The results of this pooled analysis indicated that sildenafil is a clinically effective and well-tolerated treatment for ED regardless of patient age, including those aged $\geq 75$ years. In the current article, data from 38 randomised, double-blind, placebo-controlled, flexible-dose, sildenafil trials were used to evaluate the effects of patient ethnicity and age on the efficacy and safety of sildenafil for the treatment of ED.

\section{2 | METHODS}

Of the 74 double-blinded, placebo-controlled, sildenafil clinical trials included in a Pfizer clinical data repository, 38 trials had a flexibledose design, included the self-reported ethnicity of the enrolled men, and collected baseline and endpoint data for the International Index of Erectile Function (IIEF) ${ }^{6}$ for men with ED who were randomised to sildenafil or placebo; 37 of these 38 flexible-dose trials collected Global Assessment Question (GAQ; "Did the treatment improve your erections?") data at endpoint. In the present post hoc analysis, data were pooled from these 38 double-blind, placebo-controlled, flexibledose trials to assess the efficacy and safety of sildenafil according to ethnicity and age. The starting sildenafil dose was $50 \mathrm{mg}$, to be taken approximately 1 hour before sexual activity but not more than once daily, with subsequent dose adjustment to $100 \mathrm{mg}$ or $25 \mathrm{mg}$ as needed. The majority of the trials included a 12-week treatment period and enrolled men with ED of 3-6-months' duration who were in a stable heterosexual relationship. Men taking nitrate therapy or nitric oxide donors and those with severe cardiac failure, unstable angina, or recent stroke or myocardial infarction were excluded from enrolment. Each study was conducted in accordance with Good Clinical Practice Guidelines and the Declaration of Helsinki. All trial protocols were approved by appropriate local ethics committees or institutional review boards. Each subject provided written informed consent before trial enrolment.

The data were pooled for the overall population and also stratified by self-reported ethnicity (white, black, and Asian) and by age at baseline ( $\leq 45,46-60$, and $\geq 61$ years). Efficacy analyses included all men with ED who were randomised to treatment and had baseline and $\geq 1$ postbaseline assessment of the IIEF efficacy outcome or a response to the GAQ at endpoint. Safety analyses (ie, treatment-related adverse events) included all randomised men who received at least one dose of study medication. Treatment efficacy was assessed based on patientreported scores for the IIEF erectile function (IIEF-EF) domain (score range: 1-30, with lower scores indicating greater ED severity), IIEF question 3 (Q3: achieving erection; score range: 0-5) and IIEF question 4 (Q4; maintenance of erection; score range: 0-5) at baseline and endpoint (38 trials), ${ }^{6}$ and a Global Assessment Question (GAQ: "Did the treatment improve your erections?") at endpoint (37 trials). Adverse events occurring during each study and up to 7 days after the last dose of study medication were reported.

\section{What's known}

Sildenafil is a well-tolerated and effective first-line therapy for erectile dysfunction, as evidenced by its almost two decades of use in clinical practice. A large body of sildenafil clinical trial data provides important information that can be used to facilitate the clinical management of patients with erectile dysfunction. Pooled analyses from 48 randomised, double-blind, placebo-controlled, flexible-dose sildenafil trials showed the efficacy and tolerability of sildenafil are unaffected by age.

\section{What's new}

The treatment of erectile dysfunction with a flexible-dose of sildenafil was effective and well-tolerated vs. placebo treatment in white, black and Asian men, regardless of their ethnic background. Although men of all ages and ethnicities achieve a significant treatment effect with sildenafil vs. placebo, there are some variations in the efficacy and safety of sildenafil vs. placebo as a result of treatment-by-ethnicity and treatment-by-age interactions.

For each IIEF outcome, an analysis of covariance (ANCOVA) model was applied to the change from baseline to endpoint (or termination with last-observation-carried-forward [LOCF] method). The ANCOVA model included baseline value, study, treatment, age group, ethnic group, three comorbidity indicators (CVD/HTN, depression, and diabetes), interaction of treatment by age group, interaction of treatment by ethnic group, and interaction of treatment by ethnic and age group. For each IIEF outcome, the least squares (LS) mean, the standard error (SE) of the LS mean, and $P$ values for the treatment comparison between sildenafil and PBO and a type 3 test for main effects and the interaction of treatment by age and/or ethnic group were reported. In addition, the treatment difference was compared between age groups and between ethnic groups separately. For the GAQ, a logistic regression model was applied. The logistic regression analysis included study, treatment, age group, ethnic group, three comorbidity indicators (CVD/HTN, depression and diabetes), interaction of treatment by age group, interaction of treatment by ethnic group, and interaction of treatment by ethnic and age group. The odds ratio (OR; exponentiated estimate) for sildenafil vs. PBO, the $95 \%$ confidence interval $(\mathrm{Cl})$ of the $\mathrm{OR}$, the $P$ value for the treatment comparison, and the likelihood-ratio statistic for the type 3 test for main effects and interactions were assessed. In addition, the treatment difference OR was compared between age groups and between ethnic groups separately. All statistical tests were 2 -sided with a $5 \%$ level of significance. No adjustment was made for multiple comparisons.

\section{3 | MAIN OUTCOME MEASURES}

Patient-reported quantitative scores for the IIEF erectile function domain, Q3 (achieving erection), and Q4 (maintenance of erection) 
at baseline and endpoint, together with the qualitative yes or no response to the GAQ at endpoint, were the main outcome measures.

\section{4 | RESULTS}

\section{1 | Patients}

A total of 7834 men were included in the present post hoc analysis, with 4120 men treated with sildenafil (white: 2740; black: 407; Asian: 973) and 3714 men treated with PBO (white: 2671 black: 385; Asian: 658). The mean age and IIEF scores at baseline within each ethnicity group and within each age group were comparable for men treated with sildenafil and men treated with PBO (Table 1). The mean duration of ED at baseline was 4-5 years across the three ethnicity groups. The mean scores at baseline for the IIEF-EF domain, IIEF Q3 and IIEF Q4 generally decreased with increasing age in each ethnic group. The modal dose of sildenafil during these flexible-dose trials was predominantly $100 \mathrm{mg}$ in each ethnic group (white: 64\%; black: 62\%; Asian: 58\%) and in each age group ( $\leq 45$ years: $49 \%$ to $61 \%$; $46-60$ years: $56 \%-69 \%$; $\geq 61$ years: $56 \%-65 \%$ ).

\section{2 | Efficacy outcomes}

Based on type 3 tests from the ANCOVA model analysing quantitative IIEF outcomes, significant treatment-by-age and treatment-byethnicity interactions were observed for the change from baseline in IIEF-EF domain, Q3 (achieving erection), and Q4 (maintenance of erection) scores (all $P<.05$; Table 2 ). In addition, significant treatment differences were observed in the change from baseline in the IIEF-EF domain, Q3, and Q4 scores between men with vs. men without CVD/ HTN $(P<.05)$ and men with vs. men without diabetes $(P<.0001)$, but not between men with vs. men without depression ( $P \geq .2463)$. Treatment differences were highest in men aged $\geq 61$ years and lowest in men aged $\leq 45$ years. The treatment difference was the greatest in white men and the lowest in black men.

All treatment differences significantly favoured sildenafil vs. PBO in the change from baseline to endpoint in the IIEF-EF domain score for each ethnic, age and ethnic-age group (all $P$ values <.02; Table 3). Within the three ethnic groups, the treatment comparison for sildenafil vs. PBO in IIEF-EF domain scores was significantly greater for white

TABLE 1 Patient characteristics at baseline according to ethnic and age groups

\begin{tabular}{|c|c|c|c|c|c|c|}
\hline & \multicolumn{3}{|l|}{ Placebo } & \multicolumn{3}{|l|}{ Sildenafil } \\
\hline Mean (SD) age, years Range & $\begin{array}{l}\mathrm{n}=2671 \\
55.9(11.0) \\
18-89\end{array}$ & $\begin{array}{l}n=385 \\
52.7(10.8) \\
23-81\end{array}$ & $\begin{array}{l}n=658 \\
52.2(11.3) \\
24-78\end{array}$ & $\begin{array}{l}n=2740 \\
56.3(10.9) \\
19-87\end{array}$ & $\begin{array}{l}n=407 \\
53.4(9.5) \\
21-78\end{array}$ & $\begin{array}{l}n=973 \\
50.6(11.9) \\
24-86\end{array}$ \\
\hline$\leq 45$ years & $\begin{array}{l}n=450 \\
38.7(5.7) \\
18-45\end{array}$ & $\begin{array}{l}n=94 \\
8.4(5.7) \\
23-45\end{array}$ & $\begin{array}{l}n=190 \\
38.2(5.3) \\
24-45\end{array}$ & $\begin{array}{l}n=419 \\
38.6(5.7) \\
19-45\end{array}$ & $\begin{array}{l}n=77 \\
39.2(5.0) \\
21-45\end{array}$ & $\begin{array}{l}n=350 \\
37.7(5.7) \\
24-45\end{array}$ \\
\hline $46-60$ years & $\begin{array}{l}n=1245 \\
53.4(4.2) \\
46-60\end{array}$ & $\begin{array}{l}n=204 \\
53.2(4.2) \\
46-60\end{array}$ & $\begin{array}{l}n=300 \\
43.4(4.3) \\
46-60\end{array}$ & $\begin{array}{l}n=1299 \\
53.5(4.2) \\
46-60\end{array}$ & $\begin{array}{l}n=234 \\
53.1(4.1) \\
46-60\end{array}$ & $\begin{array}{l}n=401 \\
53.3(4.4) \\
46-60\end{array}$ \\
\hline$\geq 61$ years & $\begin{array}{l}n=976 \\
67.1(4.8) \\
61-89\end{array}$ & $\begin{array}{l}n=87 \\
66.8(4.8) \\
61-81\end{array}$ & $\begin{array}{l}n=168 \\
66.0(4.2) \\
61-78\end{array}$ & $\begin{array}{l}n=1022 \\
67.2(4.8) \\
61-87\end{array}$ & $\begin{array}{l}n=96 \\
65.5(3.4) \\
61-78\end{array}$ & $\begin{array}{l}n=222 \\
66.1(4.6) \\
61-86\end{array}$ \\
\hline \multicolumn{7}{|l|}{ EF domain ${ }^{a}$} \\
\hline$\leq 45$ years & $14.6(6.9)$ & $14.4(6.0)$ & $14.2(4.6)$ & $14.3(7.0)$ & $16.3(6.2)$ & $15.0(4.2)$ \\
\hline $46-60$ years & $12.6(6.8)$ & $13.8(6.4)$ & $12.6(5.3)$ & $12.7(6.9)$ & $13.1(6.5)$ & $13.5(4.8)$ \\
\hline$\geq 61$ years & $10.9(6.8)$ & $11.6(7.1)$ & $12.2(6.3)$ & $10.9(6.7)$ & $12.0(7.5)$ & $12.2(5.7)$ \\
\hline \multicolumn{7}{|l|}{$\mathrm{Q}^{\mathrm{a}}$} \\
\hline$\leq 45$ years & $2.7(1.6)$ & $2.6(1.5)$ & $2.5(1.3)$ & $2.6(1.6)$ & $3.0(1.5)$ & $2.6(1.3)$ \\
\hline $46-60$ years & $2.3(1.5)$ & $2.6(1.4)$ & $2.1(1.3)$ & $2.3(1.5)$ & $2.3(1.5)$ & $2.3(1.3)$ \\
\hline$\geq 61$ years & $1.9(1.5)$ & $1.9(1.5)$ & $2.0(1.4)$ & $1.9(1.5)$ & $2.0(1.6)$ & $1.9(1.3)$ \\
\hline \multicolumn{7}{|l|}{$\mathrm{Q}^{\mathrm{a}}$} \\
\hline
\end{tabular}

ED, erectile dysfunction; IIEF, 15-item International Index of Erectile Function; SD, standard deviation. Data from 38 double-blind, placebo-controlled, flexible-dose trials. ${ }^{\mathrm{a}} \mathrm{Q} 3=\mathrm{IIEF}$ question 3 (achieving erection; score range 0-5); Q4=IIEF question 4 (maintaining erection; score range 0-5); EF Domain=6item erectile function domain (score range: 1-30). 
TABLE 2 Change from baseline to endpoint in IIEF scores ${ }^{a}$ and improved erections at endpoint for GAQ

\begin{tabular}{|c|c|c|c|c|c|c|c|}
\hline Outcome & $\begin{array}{l}\text { Overall treatment } \\
\text { difference (Sildenafil } \\
\text { vs. PBO) }\end{array}$ & $\begin{array}{l}\text { Overall age } \\
\text { group } \\
\text { difference }\end{array}$ & $\begin{array}{l}\text { Overall } \\
\text { ethnic group } \\
\text { difference }\end{array}$ & $\begin{array}{l}\text { Treatment-by-age } \\
\text { group interaction }\end{array}$ & $\begin{array}{l}\text { Treatment-by-ethnic } \\
\text { group interaction }\end{array}$ & $\begin{array}{l}\text { Comorbidity } \\
\text { effect }\end{array}$ & $\begin{array}{l}\text { Study } \\
\text { effect }\end{array}$ \\
\hline $\begin{array}{l}\text { IIEF Q3 (achieving } \\
\text { erection) }\end{array}$ & $P<.0001$ & $P<.0001$ & $P=.0001$ & $P=.0411$ & $P=.0002$ & $\begin{array}{l}\text { CVD/HTN: } \\
P=.0170 \\
\text { Diabetes: } \\
P<.0001 \\
\text { Depression: } \\
P=.6146\end{array}$ & $P<.0001$ \\
\hline $\begin{array}{l}\text { GAQ ("Did the } \\
\text { treatment improve } \\
\text { your erections?") }\end{array}$ & $P<.0001$ & $P<.0001$ & $P<.0001$ & $P=.5331$ & $P=.0004$ & $\begin{array}{l}\text { CVD } / \mathrm{HTN}: \\
P=.2049 \\
\text { Diabetes: } \\
P<.0001 \\
\text { Depression: } \\
P=.1368\end{array}$ & $P<.0001$ \\
\hline
\end{tabular}

ANCOVA, analysis of covariance; GAQ, global assessment question; IIEF, International Index of Erectile Function; CVD/HTN, cardiovascular disease and/ or hypertension; PBO, placebo. Data from 38 (IIEF) or 37 (GAQ) double-blind, PBO-controlled, flexible-dose trials; includes only men with baseline and

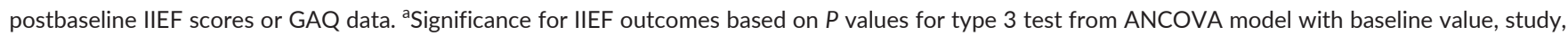
treatment, age group, ethnic group, three comorbidity indicators (CVD/HTN, depression and diabetes), treatment-by-age group interaction, treatment-byethnic group interaction and treatment-by-age group-ethnic group interaction (2-sided at $5 \%$ significance level). ${ }^{b}$ Significance for GAQ based on likelihood ratio $P$ values for type 3 analysis from logistic regression model with study, treatment, age group, ethnic group, three comorbidity indicators (CVD/HTN, depression and diabetes), treatment-by-age group interaction, treatment-by-ethnic group interaction, and treatment-by-ethnic group and age group interaction (2-sided at $5 \%$ significance level).

vs. black men $(P<.0001)$, white vs. Asian men $(P=.0163)$ and Asian vs. black men $(P=.0036)$. Within the three age groups, the comparison for sildenafil vs. $P B O$ in IIEF-EF domain scores was significantly greater for men aged $\geq 61$ years vs. men aged $\leq 45$ years $(P=.0103)$ and for men aged $46-60$ years vs. men aged $\leq 45$ years $(P=.0217)$. Similar significant results were observed for comparisons in IIEF Q3 and Q4 scores for sildenafil vs. PBO within the ethnicity and age groups (data not shown), except the treatment comparison between white vs. Asian men was not significant (Q3: $P=.8561 ; \mathrm{Q} 4: P=.8400$ ).

The results of type 3 tests from the logistic regression analysis of the qualitative GAQ indicated a significant treatment-by-ethnicity interaction $(P=.0004)$ and a non-significant treatment-by-age interaction $(P=.5331)$ (Table 2). Significant differences were observed for the GAQ between men with vs. men without diabetes $(P<.0001)$, but not between men with vs. men without CVD/HTN ( $P=.2049)$ or depression ( $P=.1368)$.

The OR for sildenafil vs. PBO on the GAQ at endpoint was significant in each ethnic group and in each age group (all $P<.0001$; Table 4). The ORs for sildenafil vs. PBO were similar in men aged $\leq 45$ years $(\mathrm{OR}=7.9)$, 46-60 years $(\mathrm{OR}=8.9)$, and $\geq 61$ years (OR=10.1). Each comparison between age groups was not significant. The ORs for sildenafil vs. $P B O$ in white men $(O R=11.2)$ and Asian men $(O R=12.4)$ were greater than the OR for black men $(\mathrm{OR}=5.1)$. Treatment comparisons between ethnic groups were significant for white vs. black men $(P=.0001)$ and for Asian vs. black men $(P=.0001)$.

\section{3 | Adverse events}

Treatment with sildenafil was well tolerated in each ethnic and age group. The most common treatment-related adverse events (ie, $\geq 3 \%$ incidence in either treatment group and with a greater incidence with sildenafil than with placebo) are listed in Table 5. Overall, treatment-related adverse events were predominantly mild in severity. Headache was the most common treatment-related adverse event in white and black men, whereas flushing was the most common treatment-related adverse event in Asian men. In men aged $\leq 45$ years, the incidence of treatmentrelated headache was higher in black men (20.8\%) than in white (13.4\%) or Asian (12.6\%) men. The incidence of headache was slightly higher in white men than in black or Asian men in the 46-60-year and $\geq 61$-year age groups. Of note, flushing was not a common treatment-related adverse event among black men in any age group. 
TABLE 3 Treatment difference (sildenafil vs. PBO) for the change from baseline to endpoint in IIEF-EF domain score in ethnic, age and ethnic-age groups

\begin{tabular}{|c|c|c|c|}
\hline Comparison (Sildenafil vs. PBO) & $\begin{array}{l}\text { LS mean (SE) treatment } \\
\text { difference }\end{array}$ & $95 \% \mathrm{Cl}$ & $P$ Value $^{\mathrm{a}}$ \\
\hline Overall & $6.4(0.2)$ & $6.0-6.9$ & $<.0001$ \\
\hline \multicolumn{4}{|l|}{ Ethnic groups } \\
\hline White & $7.8(0.2)$ & 7.3-8.2 & $<.0001$ \\
\hline Black & $4.8(0.6)$ & $3.8-5.9$ & $<.0001$ \\
\hline Asian & $6.7(0.4)$ & $6.0-7.5$ & $<.0001$ \\
\hline \multicolumn{4}{|l|}{ Between ethnic groups } \\
\hline White vs. Black & $2.9(0.6)$ & $1.8-4.1$ & $<.0001$ \\
\hline White vs. Asian & $1.0(0.4)$ & $0.2-1.8$ & .0163 \\
\hline Black vs. Asian & $-1.9(0.7)$ & $-3.2--0.6$ & .0036 \\
\hline \multicolumn{4}{|l|}{ Age groups } \\
\hline$\leq 45$ years & $5.5(0.5)$ & $4.6-6.4$ & $<.0001$ \\
\hline $46-60$ years & $6.7(0.3)$ & $6.2-7.3$ & $<.0001$ \\
\hline$\geq 61$ years & $7.1(0.4)$ & $6.3-7.9$ & $<.0001$ \\
\hline \multicolumn{4}{|l|}{ Between age groups } \\
\hline$\leq 45$ vs. $46-60$ years & $-1.2(0.5)$ & $-2.3--0.2$ & .0217 \\
\hline$\leq 45$ vs. $\geq 61$ years & $-1.6(0.6)$ & $-2.8--0.4$ & .0103 \\
\hline $46-60$ vs. $\geq 61$ years & $-0.3(0.5)$ & $-1.4-0.7$ & .6645 \\
\hline \multicolumn{4}{|l|}{ Ethnic-age groups } \\
\hline White $\leq 45$ years & $8.5(0.5)$ & $7.6-9.5$ & $<.0001$ \\
\hline White $46-60$ years & $7.5(0.3)$ & $6.9-8.0$ & $<.0001$ \\
\hline White $\geq 61$ years & $7.3(0.3)$ & $6.6-7.9$ & $<.0001$ \\
\hline Black $\leq 45$ years & $2.7(1.1)$ & $0.6-4.9$ & .0139 \\
\hline Black $46-60$ years & $5.2(0.7)$ & $3.9-6.5$ & $<.0001$ \\
\hline Black $\geq 61$ years & $6.6(1.0)$ & $4.6-8.6$ & $<.0001$ \\
\hline Asian $\leq 45$ years & $5.2(0.6)$ & $4.0-6.5$ & $<.0001$ \\
\hline Asian $46-60$ years & $7.6(0.5)$ & $6.5-8.6$ & $<.0001$ \\
\hline Asian $\geq 61$ years & $7.4(0.7)$ & $6.0-8.8$ & $<.0001$ \\
\hline
\end{tabular}

ANCOVA, analysis of covariance; $\mathrm{Cl}$, confidence interval; IIEF-EF domain, International Index of Erectile Function erectile function domain; LS, least squares; PBO, placebo. Data from 38 double-blind. PBO-controlled, flexible-dose trials; includes only men with baseline and postbaseline IIEF-EF scores. ${ }^{a} P$ value from ANCOVA model with baseline value, study, treatment, age group, ethnic group, three comorbidity indicators (CVD/HTN, depression and diabetes), treatment-by-age group interaction, treatment-by-ethnic group interaction, and treatment-by-ethnic group and age group interaction (2sided at $5 \%$ significance level).

\section{5 | DISCUSSION}

In the current analyses, data for 7834 men from 38 randomised, double-blind, placebo-controlled, flexible-dose, sildenafil trials were used to evaluate the effects of patient ethnicity (white, black or Asian) and age ( $\leq 45,46-60$, or $\geq 61$ years) on the efficacy and safety of sildenafil for the treatment of ED. The results of this pooled analysis demonstrated that overall treatment differences for sildenafil vs. PBO for the IIEF-EF domain and the GAQ were significant for each ethnic and each age group (all $P<.0001$ ). However, significant treatmentby-ethnicity and treatment-by-age interactions were observed for the change from baseline in quantitative IIEF-EF domain scores with sildenafil vs. PBO (all $P<.05$ ). A significant treatment-by-ethnicity interaction also was observed for the treatment difference in the qualitative GAQ $(P=.0004)$. The types and incidences of treatmentrelated adverse events were generally similar in white, black and Asian men, with some variations among the three age groups. Overall, these results demonstrate the efficacy and safety of sildenafil in white, black and Asian men in all three age groups, with some variations in treatment effects according to ethnicity and age.

The strengths of the current analyses of the efficacy of sildenafil are that the statistical models included a treatment-by-ethnicity interaction and also adjusted for various ED-associated comorbidities ${ }^{2}$ that may have an effect on ED treatment responsiveness. ${ }^{7}$ The efficacy and safety data also were collected during trials with a similar double-blind, PBO-controlled, flexible-dose design. Furthermore, efficacy results were assessed with both the quantitative change from 
TABLE 4 Treatment difference (sildenafil vs. PBO) for the percentage of men with improved erections on GAQ in ethnic, age and ethnic-age groups

\begin{tabular}{|c|c|c|c|}
\hline $\begin{array}{l}\text { Comparison (Sildenafil vs. } \\
\text { PBO) }\end{array}$ & $\begin{array}{l}\text { Odds ratio } \\
\text { for treatment } \\
\text { difference }\end{array}$ & $95 \% \mathrm{Cl}$ & $P$ value \\
\hline Overall & 8.9 & $7.6-10.5$ & $<.0001$ \\
\hline \multicolumn{4}{|l|}{ Ethnic groups ${ }^{a}$} \\
\hline White & 11.2 & $9.5-13.2$ & $<.0001$ \\
\hline Black & 5.1 & $3.5-7.4$ & $<.0001$ \\
\hline Asian & 12.4 & $9.5-16.1$ & $<.0001$ \\
\hline \multicolumn{4}{|l|}{ Between ethnic groups ${ }^{\text {b }}$} \\
\hline White vs. Black & 2.2 & $1.5-3.3$ & .0001 \\
\hline White vs. Asian & 0.9 & $0.7-1.2$ & .5354 \\
\hline Black vs. Asian & 0.4 & $0.3-0.7$ & .0001 \\
\hline \multicolumn{4}{|l|}{ Age groups $^{a}$} \\
\hline$\leq 45$ years & 7.9 & $5.7-10.8$ & $<.0001$ \\
\hline $46-60$ years & 8.9 & $7.2-11.0$ & $<.0001$ \\
\hline$\geq 61$ years & 10.1 & $7.5-13.6$ & $<.0001$ \\
\hline \multicolumn{4}{|l|}{ Between age groups ${ }^{b}$} \\
\hline$\leq 45$ vs. $46-60$ years & 0.9 & $0.6-1.3$ & .5219 \\
\hline$\leq 45$ vs. $\geq 61$ years & 0.8 & $0.5-1.2$ & .2624 \\
\hline $46-60$ vs. $\geq 61$ years & 0.9 & $0.6-1.3$ & .5032 \\
\hline \multicolumn{4}{|l|}{ Ethnic-age groups ${ }^{a}$} \\
\hline White $\leq 45$ years & 16.7 & $11.5-24.3$ & $<.0001$ \\
\hline White $46-60$ years & 10.0 & $8.2-12.2$ & $<.0001$ \\
\hline White $\geq 61$ years & 8.5 & $6.8-10.7$ & $<.0001$ \\
\hline Black $\leq 45$ years & 3.2 & $1.5-6.8$ & .0024 \\
\hline Black $46-60$ years & 5.4 & $3.4-8.6$ & $<.0001$ \\
\hline Black $\geq 61$ years & 7.6 & $3.7-15.3$ & $<.0001$ \\
\hline Asian $\leq 45$ years & 9.1 & $5.9-14.0$ & $<.0001$ \\
\hline Asian $46-60$ years & 13.0 & $8.8-19.2$ & $<.0001$ \\
\hline Asian $\geq 61$ years & 16.0 & $9.5-26.9$ & $<.0001$ \\
\hline
\end{tabular}

$\mathrm{Cl}$, confidence interval; GAQ, Global assessment question; PBO, placebo. Data from 37 double-blind. PBO-controlled, flexible-dose trials; includes only men with GAQ data at endpoint. ${ }^{a}$ Liklihood ratio $P$ value for type 3 analysis from logistic regression model with study, treatment, age group, ethnic group, three comorbidity indicators (CVD/HTN, depression, and diabetes), treatment-by-age group interaction, treatment-by-ethnic group interaction and treatment-by-ethnic group and age group interaction (2sided at $5 \%$ significance level). ${ }^{b}$ Within-group $P$ value based on a ratio of the odds ratios for treatment difference (sildenafil vs. PBO).

baseline in IIEF scores and the qualitative GAQ. Possible limitations include that the 38 clinical trials enrolled only men with ED who did not have certain prespecified concomitant diseases and those who were in a stable heterosexual relationship. Therefore, the results may not reflect those for all men with ED.

It is important to evaluate the efficacy and safety of treatments for ED in men from various ethnic and age populations because different ethnic and age groups have different prevalence rates of ED-associated comorbid diseases and other risk factors for ED. For example, in the United States, the age-adjusted prevalence of HTN is greater in blacks than in whites ${ }^{8}$ and the age-adjusted prevalence of diabetes is higher in blacks or Asians than in whites. ${ }^{9}$ Furthermore, the cultural and religious beliefs of different ethnic groups can have an impact on the diagnosis and treatment-seeking behaviour of men with ED.

Several small-scale, PBO-controlled studies of the efficacy and safety of sildenafil previously were conducted in black men ${ }^{10}$ and in Asian men ${ }^{11-15}$ with ED. In 246 black American men with ED evaluated by Young et al. in a double-blind, PBO-controlled, flexibledose trial, approximately $60 \%$ reported HTN and $28 \%$ reported diabetes. ${ }^{10}$ After 6 weeks of treatment, IIEF-EF domain, Q3, and Q4 scores and the percentage of men indicating improved erections on the GAQ were significantly greater with sildenafil vs. PBO. Treatment with sildenafil was well-tolerated in black men, with only $22(18 \%)$ men experiencing treatment-related adverse events. ${ }^{10}$ Four PBOcontrolled studies assessing flexible-dose sildenafil for the treatment of ED in Asian men from Malaysia/Singapore/the Philippines, Thailand, Taiwan, or Korea (sample size range: 125-254 men) demonstrated significant improvements in IIEF-EF domain, Q3, and Q4 scores and significantly improved erections on the GAQ with sildenafil vs. PBO after 8-12 weeks of treatment. ${ }^{11-14}$ The incidence of treatment-related adverse events in these four studies ranged from $23 \%$ to $56 \%$ in the sildenafil group and from $10 \%$ to $21 \%$ in the PBO group; all or most adverse events in the sildenafil group were mild in nature. Another small-scale, 6-week, PBO-controlled, flexible-dose study evaluated the efficacy and safety of sildenafil in 155 men from Malaysia, Thailand and Singapore with ED and 1 or more comorbidities (ie, mild-moderate HTN, diabetes and dyslipidaemia). ${ }^{15}$ Despite the increased cardiovascular risk associated with one or more comorbidities, Asian men with ED treated with sildenafil for 6 weeks demonstrated significant improvements in IIEF-EF, Q3 and Q4 scores and a significantly greater percentage reported improved erections on the GAQ compared with PBO. The incidence of treatment-related adverse events was $10 \%$ in the sildenafil group and $10 \%$ in the PBO group. $^{15}$

The results of the present analysis of 7834 men provide strong validation of the efficacy and safety of sildenafil vs. PBO in the treatment of ED in white, black and Asian men, regardless of age. Comparisons between different ethnic and age groups indicate some variations in efficacy outcomes and adverse events, but each group demonstrates a significant treatment difference favouring sildenafil vs. PBO. Although individual patients may have different ethnic backgrounds, different ages and different concomitant diseases, the clinical evidence indicates that sildenafil significantly improves erectile function and is a well-tolerated treatment option for men with ED.

\section{6 | CONCLUSIONS}

Sildenafil is an effective and well-tolerated treatment for ED regardless of ethnicity or age. However, sildenafil treatment effects can vary with patient ethnicity and age. 
TABLE 5 Most common treatmentrelated adverse events ${ }^{\mathrm{a}}$ in ethnic and ethnic-age groups

\begin{tabular}{|c|c|c|}
\hline \multirow[b]{2}{*}{ Group } & \multicolumn{2}{|l|}{ Adverse event, $n$ (\%) } \\
\hline & PBO & Sildenafil \\
\hline \multicolumn{3}{|l|}{ Ethnic groups } \\
\hline White & $\begin{array}{l}\mathrm{n}=2671 \\
\text { Headache: } 70(2.6) \\
\text { Flushing: } 23(0.9) \\
\text { Dyspepsia: } 9(0.3)\end{array}$ & $\begin{array}{l}\mathrm{n}=2740 \\
\text { Headache: } 323 \text { (11.8) } \\
\text { Flushing: } 266(9.7) \\
\text { Dyspepsia: } 100(3.6)\end{array}$ \\
\hline Black & $\begin{array}{l}\mathrm{n}=385 \\
\text { Headache: } 8(2.1)\end{array}$ & $\begin{array}{l}\mathrm{n}=407 \\
\text { Headache: } 46 \text { (11.3) }\end{array}$ \\
\hline Asian & $\begin{array}{l}\mathrm{n}=658 \\
\text { Flushing: } 20(3.0) \\
\text { Headache: } 26(4.0) \\
\text { Dizziness: } 19(2.9) \\
\text { Nasal congestion: } 4(0.6)\end{array}$ & $\begin{array}{l}\mathrm{n}=973 \\
\text { Flushing: } 124(12.7) \\
\text { Headache: } 69 \text { (7.1) } \\
\text { Dizziness: } 55 \text { (5.7) } \\
\text { Nasal congestion: } 31 \text { (3.2) }\end{array}$ \\
\hline \multicolumn{3}{|l|}{ Ethnic-age groups } \\
\hline White $\leq 45$ years & $\begin{array}{l}\mathrm{n}=450 \\
\text { Headache: } 14(3.1) \\
\text { Flushing: } 7 \text { (1.6) } \\
\text { Dyspepsia: } 4 \text { (0.9) } \\
\text { Nasal congestion: } 1(0.2)\end{array}$ & $\begin{array}{l}\mathrm{n}=419 \\
\text { Headache: } 56(13.4) \\
\text { Flushing: } 40 \text { (9.5) } \\
\text { Dyspepsia: } 20 \text { (4.8) } \\
\text { Nasal congestion: } 14 \text { (3.3) }\end{array}$ \\
\hline Black $\leq 45$ years & $\begin{array}{l}\mathrm{n}=94 \\
\text { Headache: } 2(2.1) \\
\text { Dyspepsia: } 0\end{array}$ & $\begin{array}{l}\mathrm{n}=77 \\
\text { Headache: } 16(20.8) \\
\text { Dyspepsia: } 3 \text { (3.9) }\end{array}$ \\
\hline Asian $\leq 45$ years & $\begin{array}{l}\mathrm{n}=190 \\
\text { Flushing: } 5(2.6) \\
\text { Headache: } 8(4.2) \\
\text { Dizziness: } 7(3.7)\end{array}$ & $\begin{array}{l}\mathrm{n}=350 \\
\text { Flushing: } 44(12.6) \\
\text { Headache: } 23(6.6) \\
\text { Dizziness: } 20(5.7)\end{array}$ \\
\hline White $46-60$ years & $\begin{array}{l}\mathrm{n}=1245 \\
\text { Headache: } 33(2.7) \\
\text { Flushing: } 10(0.8) \\
\text { Dyspepsia: } 1(<0.1)\end{array}$ & $\begin{array}{l}\mathrm{n}=1299 \\
\text { Headache: } 161(12.4) \\
\text { Flushing: } 125(9.6) \\
\text { Dyspepsia: } 47(3.6)\end{array}$ \\
\hline Black $46-60$ years & $\begin{array}{l}n=204 \\
\text { Headache: } 4 \text { (2.0) }\end{array}$ & $\begin{array}{l}n=234 \\
\text { Headache: } 23 \text { (9.8) }\end{array}$ \\
\hline Asian $46-60$ years & $\begin{array}{l}\mathrm{n}=300 \\
\text { Headache: } 9(3.0) \\
\text { Dizziness: } 6 \text { (2.0) } \\
\text { Nasal congestion: } 3 \text { (1.0) }\end{array}$ & $\begin{array}{l}\mathrm{n}=401 \\
\text { Headache: } 29(7.2) \\
\text { Dizziness: } 20 \text { (5.0) } \\
\text { Nasal congestion: } 14(3.5)\end{array}$ \\
\hline White $\geq 61$ years & $\begin{array}{l}\mathrm{n}=976 \\
\text { Headache: } 23(2.4) \\
\text { Flushing: } 6(0.6) \\
\text { Dyspepsia: } 4(0.4)\end{array}$ & $\begin{array}{l}\mathrm{n}=1022 \\
\text { Headache: } 106(10.4) \\
\text { Flushing: } 101(9.9) \\
\text { Dyspepsia: } 33(3.2)\end{array}$ \\
\hline Black $\geq 61$ years & $\begin{array}{l}\mathrm{n}=87 \\
\text { Headache: } 2 \text { (2.3) }\end{array}$ & $\begin{array}{l}\mathrm{n}=96 \\
\text { Headache: } 7 \text { (7.3) }\end{array}$ \\
\hline Asian $\geq 61$ years & $\begin{array}{l}\mathrm{n}=168 \\
\text { Headache: } 9(5.4) \\
\text { Dizziness: } 6(3.6) \\
\text { Palpitations: } 1(0.6)\end{array}$ & $\begin{array}{l}\mathrm{n}=222 \\
\text { Headache: } 17(7.7) \\
\text { Dizziness: } 15(6.8) \\
\text { Palpitations: } 7 \text { (3.2) }\end{array}$ \\
\hline
\end{tabular}

PBO,placebo. Data from 38 double-blind, PBO-controlled, flexible-dose trials. ${ }^{\mathrm{a} T}$ Treatment-related adverse events occurring in $\geq 3 \%$ of men in either treatment group and with a greater incidence with sildenafil than with placebo.

\section{ACKNOWLEDGEMENTS}

Editorial and medical writing assistance was provided by Patricia B. Leinen, PhD, of Complete Healthcare Communications, LLC, and funded by Pfizer Inc.

\section{AUTHOR CONTRIBUTIONS}

All authors contributed to this manuscript as follows: study conception and design, analysis and interpretation of data, and drafting of the manuscript or revising critically for intellectual content. 


\section{DISCLOSURES}

Dana A Ohl: Pfizer Sildenafil Advisory Board; Consultant/Surgical Trainer for Coloplast Corporation; Consultant for American Medical Systems. Vera Stecher: Employee of Pfizer Inc. Li-Jung Tseng: Employee of Pfizer Inc.

\section{REFERENCES}

1. NIH Consensus Conference. Impotence. NIH consensus development panel on impotence. JAMA. 1993;270:83-90.

2. Feldman HA, Goldstein I, Hatzichristou DG, Krane RJ, McKinlay JB. Impotence and its medical and psychosocial correlates: results of the Massachusetts Male Aging Study. J Urol. 1994;151:54-61.

3. American Urological Association. The management of erectile dysfunction: an update. 2005 (validity confirmed 2011) http://www. auanet.org/common/pdf/education/clinical-guidance/ErectileDysfunction.pdf. Accessed January 12, 2017

4. European Association of Urology.Male sexual dysfunction. 2017. https://uroweb.org/guideline/male-sexual-dysfunction/. Accessed January 31, 2017.

5. Goldstein I, Tseng L, Creanga D, Stecher V, Kaminetsky JC. Efficacy and safety of sildenafil by age in men with erectile dysfunction. J Sex Med. 2016;13:852-859.

6. Rosen RC, Riley A, Wagner G, Osterloh IH, Kirkpatrick J, Mishra A. The international index of erectile function (IIEF): a multidimensional scale for assessment of erectile dysfunction. Urology. 1997;49:822-830.

7. Suetomi T, Kawai K, Hinotsu S, et al. Negative impact of metabolic syndrome on the responsiveness to sildenafil in Japanese men. J Sex Med. 2008;5:1443-1450.

8. National Center for Health Statistics. Table 54. Hypertension among adults aged 20 and over, by selected characterristics: United States, selected years 1988-1994 through 2011-2014. 2015. https://www. cdc.gov/nchs/data/hus/2015/054.pdf.Accessed January 31, 2017.
9. National Center for Health Statistics. Table 40. Diabetes prevalence and glycemic control among adults aged 20 and over, by sex, age, and race and Hispanic origin: United States, selected years 19881994 through 2011-2014. 2015. https://www.cdc.gov/nchs/data/ hus/2015/040.pdf. Accessed January 31, 2017.

10. Young JM, Bennett C, Gilhooly P, Wessells H, Ramos DE. Efficacy and safety of sildenafil citrate $\left(\right.$ Viagra $\left.{ }^{\circledR}\right)$ in black and Hispanic American men. Urology. 2002;60(suppl 2B):39-48.

11. Tan HM, Moh CL, Mendoza JB, et al. Asian sildenafil efficacy and safety study (ASSESS-1): a double-blind, placebo-controlled, flexible-dose study of oral sildenafil in Malaysian, Singaporean, and Filipino men with erectile dysfunction. The Assess-1 Study Group. Urology. 2000;56:635-640.

12. Kongkanand A. Prevalence of erectile dysfunction in Thailand. Thai Erectile Dysfunction Epidemiological Study Group. Int J Androl. 2000;23(suppl 2):77-80.

13. Chen KK, Hsieh JT, Huang ST, et al. ASSESS-3: a randomised, doubleblind, flexible-dose clinical trial of the efficacy and safety of oral sildenafil in the treatment of men with erectile dysfunction in Taiwan. Int J Impot Res. 2001;13:221-229.

14. Choi HK, Ahn TY, Kim JJ, et al. A double-blind, randomised- placebo, controlled, parallel group, multicentre, flexible-dose escalation study to assess the efficacy and safety of sildenafil administered as required to male outpatients with erectile dysfunction in Korea. Int J Impot Res. 2003;15:80-86.

15. Buranakitjaroen P, Mangklabruks A, Leungwattanakij S, et al. Efficacy and safety of sildenafil in Asian males with erectile dysfunction and cardiovascular risk. J Med Assoc Thai. 2007;90:1100-1108.

How to cite this article: Ohl DA, Stecher V, L-J Tseng. Ethnicity and age as factors in sildenafil treatment of erectile dysfunction. International Journal of Clinical Practice.

2017;71:e12945. https://doi.org/10.1111/ijcp.12945 